\title{
New sealand
}

Google Micronation

\section{Castellano Vidallé, Ana; Maldonado Suárez, Covadonga}

Grado en Arquitectura Universidad de Alicante, Escuela Politécnica Superior, España

anita_castellano@hotmail.com; covadongams@hotmail.com

PROYECTO FIN DE CARRERA 


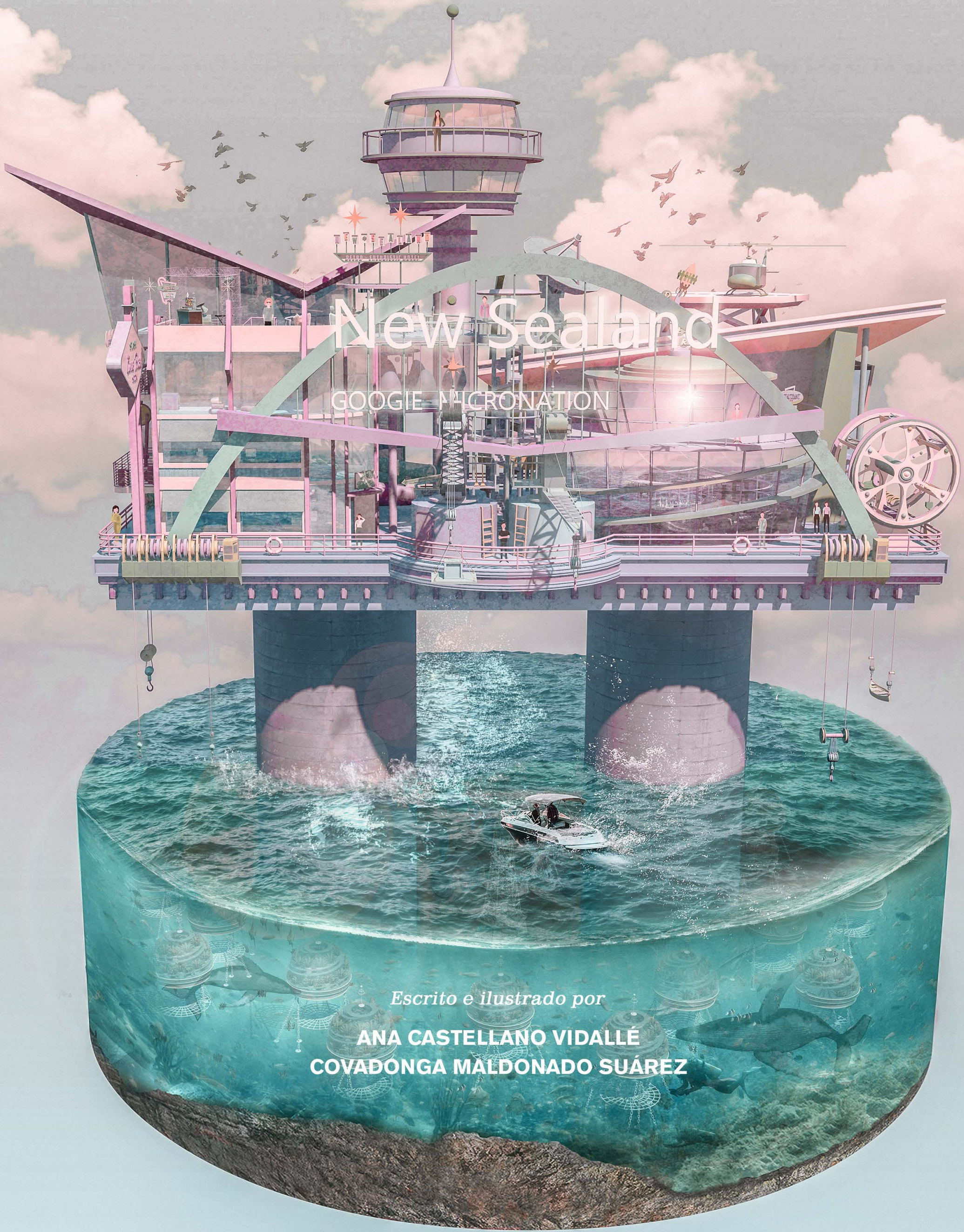


A nuestras familias

y a Enrique, María José y Carlos,

por vuestro acompañamiento y apoyo

durante este proyecto.

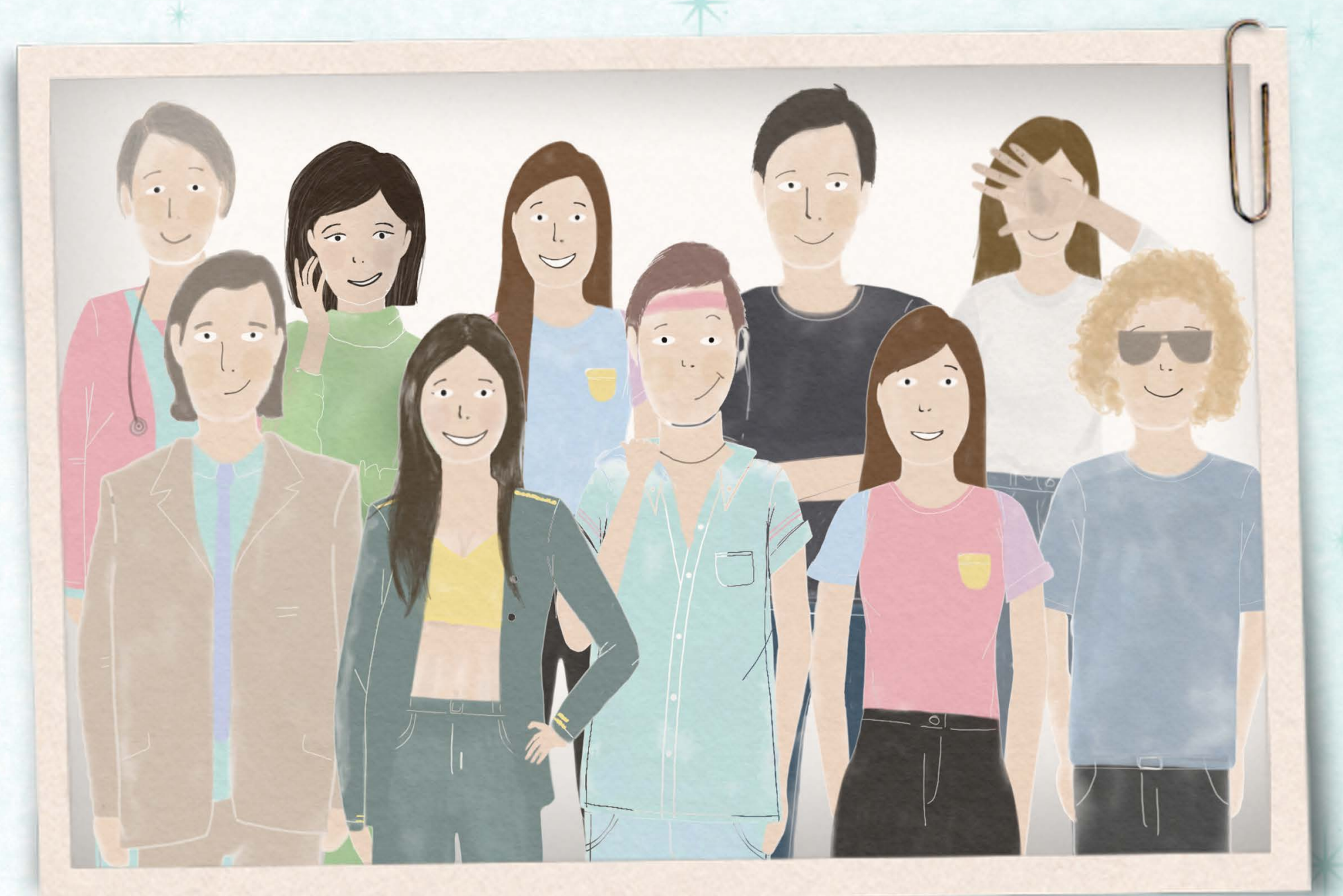

\section{$\mathbb{N} E_{i} \mathbb{W}$ SE, $\mathbb{A} L, \mathbb{A} \mathbb{N} D$}

Basada en hechos tan ficticios como la realidad misma.



por

ANA CASTELLANO VIDALIÉ

COVADONGA MALDONADO SUÁREŻ

Con los tutores de la

Universidad de Alicante

MARIA JOSÉ MARCOS

ENRIQUE NIETO

Proyecto Fin de Grado 2017-2018 
LA

807 - Palabras

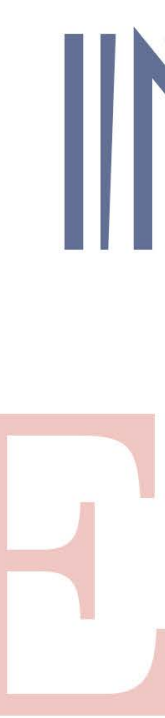

\section{$\mathbb{N} T$ TRODUC}

L MUNDO ES TAN GRANDE Y ESTÁ TAN LLENO DE GENTE, que los soñadores estamos condenados a las utopías. A ideas bienintencionadas y benevolentes con todos, que desgraciadamente siempre fracasarán en su salto de idea a propuesta. Las limitaciones de lo hegemónico y el terrible esfuerzo que supone ser normal acaban ejerciendo tal presión sobre esas propuestas que las desfiguran y reducen a tristes doctrinas que oscuramente tratan de recordar a esa idea original, bienintencionada y benevolente con todos.

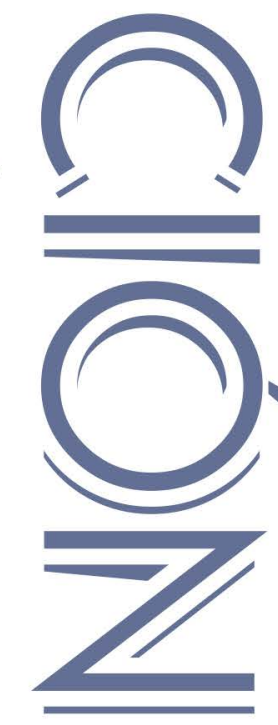

El mundo es tan grande y está tan lleno de gente que tarde o temprano comprendemos que tambien esta irremediablecia todas las preguntas tuvieran respuestas, lo no nos hizo sospechar de esta desintegración que sufria el mundo que intentábamos conocer a traves de todas las cuestiones que descubrimos. Ena rotura, Justo al día que fancia. En la adolescencia, con el corazón roto y el recuerdo de la totalidad intacta que inconscientemente imaginamos de pequenos, nos dedicamos a coleccionar experiencias que nos ayudarian a encontrar el camino correcto ante esta situacion. La adoponsables de la postura que tomamos. A esto último tambi

Contra esta fragmentación se impone

la moral universal, que incansablemente trabaja para reunificar nuestro mundo que buscan estandarizar las soluciones a los problemas. A pesar de la dificultad de este reto, el método resulta sencillo: se trata de recortar el problema, reducirlo a su propuesta más simple e inscribirlo en lo que rico que tras una serie de torpes clasificaciones. acabaŕ dando una solución incuestionable empapada de nostalgia cósmica y deseos de unificación. Desafortunadamente, la desconsideración de las subjetividades, aunque muy conveniente para simplificar el metodo, significa una condena a las pajerce desde lo que se define universal hacia lo diferente, que resulta personal y subjetivo.hacia lo diferente, que resulta per-
sonal y subjetivo.
Desde otro lado, escapando de la imposición de una moral unvirersal pero aún con el recuerdo del mundo sin fragmentar hay quiches consideran cada fragmento conjunto original. Aunque parciales e inexactas, cada una de esas maquetas gobernadas por sus propias subjetividades se convierten en laboratorios de experimentos que suceden a una escala diferente, y por tanto, tambien sufren un cambio en sus pasal. Inscrita a esta construción surge ta idea de New Sealand.

New Sealand, muy relacionada con concepto de micronación, nace como una ensonación de libertad, un experminento que idealiza el futuro pero no quiere dejar de de ese admirado porvenir

Como cualquier googie que se precie, con los pies en la tierra y mirando al cielo. se van eligiendo muy cuidadosamente todos los ingredientes que formaran parte de este experimento que se da lugar en una plata$20 \mathrm{~km}$ de la costa inglesa.

Entonces, nacidos de una colección de nuestras inquietudes e intereses, tanto como futuras arquitectas y como personas. uno a uno fueron surgiendo los singulares personajes, que ya maduros y alejados de nizar elugar y acaban adueñ́ndose deloxperimento.
En este contexto, la arquitectura es contenedor y contenido, una ocologia facilitadora de interacciones entre personas, tecnologias, máquinas, sueños y pesadillas, etc todo ello desordenado y armonizado desde la subjetividad del tiempo. Esto concede a cada personalidad la capacidad de juzgar la idoneidad de los diseños, que lejos de ser estaticos, se convierten en un poema que se perfecciona las modificaciones y aportaciones gracias a habitante. Y este poema, esta arquitectura en la que ellos conviven, resulta ser el punto donde convergen las personas y surge la comunidad, el nexo de unión de tan dispares identidades que con discrepancias que esa comunidad sea la mejor versión de sí misma y desde ahí sentar las bases de un futuro que admira el progreso y confía a la tecnología y a los avances el papel de proveedores de bienestar y fuerza, que es en cierto modo el mismo futuro que los googies soñaron y nunca llegó.

El mundo está irremediablemente roto, aunque además es tan grande y está desgastante, y a pesar de cualquier esfuerzo, también imposible volver a recomponerlo. En esta circunstancia lo importante no es el descubrimiento de esos con ellos, pues en parte eso es to due nos define como personas. 







\section{EL}

\section{DRÓLOGO}

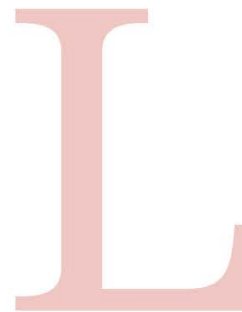

A TIERRA DE MARIE BIRD, EN LA ANTÁRTIDA, CON UNA SUPERFICIE similar a la que ocupa México, es el mayor territorio no reclamado del mundo. Si hace unos siglos se desconocía la existencia de un continente, y descubrirlo significó ese festín llamado colonizaciones, hoy en día encontrar territorios no reclamados por ningún país merece una noticia en el periódico y una entrada en Wikipedia. Bir Tawil, que ocupa una extensión igual a la mitad del territorio Suizo, se sitúa en la frontera entre Sudán y Egipto, aunque ninguno de los dos lo reclama. Suiza tampoco, supongo que hace demasiado calor para producir chocolate allí. Los clichés en la era de internet arrasan con más fuerza que nunca el sentido común: repetimos la idea que alguien nos repitió antes sin preguntarnos muchos porqués.

Durante la Segunda Guerra Mundial, el ejército británico repartió cuatro plataformas de defensa conocidas como las
Fortalezas Marinas Maunsell a pocos kilometros de la costa inglesa, aunque dos de ellas se encontraran para agues internacionales Si hay algo positivamente impresionante de la guerra es la capacidad de ensayar soluciones inmediatas, efectivas y muy ingeniosas. Y es que estos fuertes de hormigón, que consisten en dos pilare sosteniendo una plataforma superior, flotante, se construín en la costa y remolcaban hasta los bancos de arena donde se colocarian y una vez allí, en tan solo un minuto, sí, uno solamente, se instalaban los fuertes. Sacando cuentas, es más rapido instalar una plataforma de Guy Maunsell (asi se llamaba el ingeniero que las diseñó) que actualizar el iOS del iPhone. La ingeniosa construcción, sin embargo, no quedara segunda mitad de los años 50, algunos disidentes del monopolio radiofónico de la $\mathrm{BBC}$, entre los que se encontraba Roy Bates, comenzaron a mudar las radios piratas al mar. En 1966 Bates era perseguido por sus mudándose liegales, a lo que se pententó $9 \mathrm{~km}$ de la costa, ya se encontraha, que a internacionales (la frontera se situaba a los misma plataforma el Principado de
Sealand, que contando con población, territorio, gobierno y la capacidad de entablar negociaciones con otros Estados, cumplía ción de Montevideo para poder ser considerado estado.

El marketing siempre va un paso avanzado a la moda, mientras la legalidad siempre parece quedarse varios por detrás de los problemas. En nuestra era, internet ya nos ha expuesto varias veces a los vacios lelocidad de cambio en la vida moderna de la mano de la hiperconectada red no ha sido pionera en reconocer este desfase y es que la proclamación de Sealand como un estado independiente es un ejemplo de ese pasado que aún en el presente no hemos sabido recido abiertamente esta micronacín varioacontecimientos, como la visita de un embajador alemán se pueden interpretar como afirmativas.

En un mundo de hechos y demostra ciones, donde todo necesita etiqueta hertad y definitin, las en hicros de suenan a imaginaciones de patio de colegio situaciones que se ridiculizan en su propio contenido, sin un valor mas allá del anecdótico, pero toda critica es irrelevante si no se consideran las razones de la postura que se cuestiona. En este sentido, Sealand parece futuro más cierto del que queremos aceptar.

La República de las Maldivas en el Océano Indico es el país más pequeño del continente asiático, y este hecho unido al calentamiento global se ha convertido en un prave problema para los maldivos: la posibilidad de que su territorio desaparezca. En el país fuera cubierto por el man y toda del dencia actual apunta a un porvenir aún mas incierto. Este problema, del que las Maldivas sirven de ejemplo, anticipan el que muchos otros países sufrirán en un futuro no muy lejano: la perdida de sus territorios por el avance de los oceanos. Ante la eviorigen en la actividad humana derse de nuestras responsabilidades supone una derrota. En cambio, dos actitudes se presentan como fundamentales y de igual importancia: trabajar para revertir los efectos del cambio climático apostando por la sostenibilidad, y ensayar estrategias para relación a a ha ́ltima postura habitar. En esfuerzos $y$ experimentos el Seasteading Institute.

Mucho antes del 2004 las esperanzas sobre el futuro ya se habian perdido. Se perdieron cuando dejamos de vivir en el mañana y nos desenamoramos del progreque queríamos y ese futuro no llegó como lo esperábamos. Esta visión, perteneciente a la sociedad americana de los años 60 se llamaba populuxe, y su estilo se denominaba googie. Aunque el territorio googie no se extendió mucho más alla de las cafeterías, comida rápida en Los Ánosles mus de las características de este estilo y su correspondiente visión aún hoy tienen mucho que enseñarnos acerca de su forma positiva y benevolente de aproximarse al futuro. 



\section{HISTORIA DEL PRINCIPADO DE SEALAND}

1939

II Guerra Mundia

Reino Unido construyó una serie de fuertes en gó de diseñar los fuertes que en honor a su nombre se bautizaron como las Fortalezas Marinas de Maunsell

Las fortalezas se construían por completo en bancos de arena donde se hundran. Por la parte de la construcción dos torres cilíndricas de hormigón unidas por la parte superior con una plataforma, la que quedaba por encima de nivel del mar Al llegar a destino, las compuertas de la barcaza se abrian y al llenarse de agua torres y la plataforma superior por encina del

Las fortalezas eran cuatro

Rough Sands (HM Fort Roughs)

Sunk Head

$1942+$

\begin{abstract}
$1945 *$ Fin de la II Guerra Mundial Los fuertes son abandonados y caen en desuso
\end{abstract}

\section{0}

ar piratas de radio

Roy Bates ocupa el fuerte Knock John y funda la Radio Essex

Roy y su familia mudan la radio de Knock John a la fortaleza Rough Sands, donde establecen el Principado de Sealand como un estádo indépendiente
Instalación de un fuerte naval


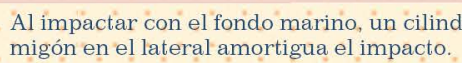

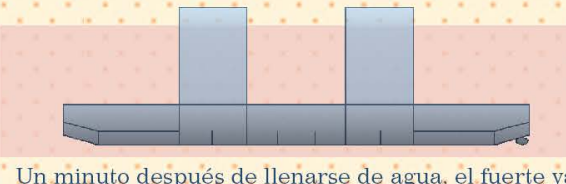

Roy Bates se convierte en príncipe y su mujer en princesa de Sealand dique seco y despues eran remolcadas a los servía sara el desplazamiento siendo el resto la fortaleza se hundia hasta tocar el fondo

minuto después de llenarse de águia, el fiuerte yn.

La Royal Army intenta desalojar a la familia Bates del fuerte Roy comienza a disparar y es arrestado.En el juicio por el incidente convence al juez que en Sealand no es aplicable la ley britanica ya que se encontraba fuera del territorio y unisdicción briltanicos Entusiasmados por el éxito, Sealand comenzó a ạcuñar sellos, monẹdas, billetes e incluso pásaportes

1968

C C Michael Bates. $\mathrm{Fl}$ contraataque de Bates es un éxito y consiguen recuperar la fortaleza detienen los atacantes como prisioneros de guerra: Tras una intervención del gobiern alemán, en la que Reino unido no quiso participar por considerar Sealand fuera de su juris diçción, los prisionerós son liberados

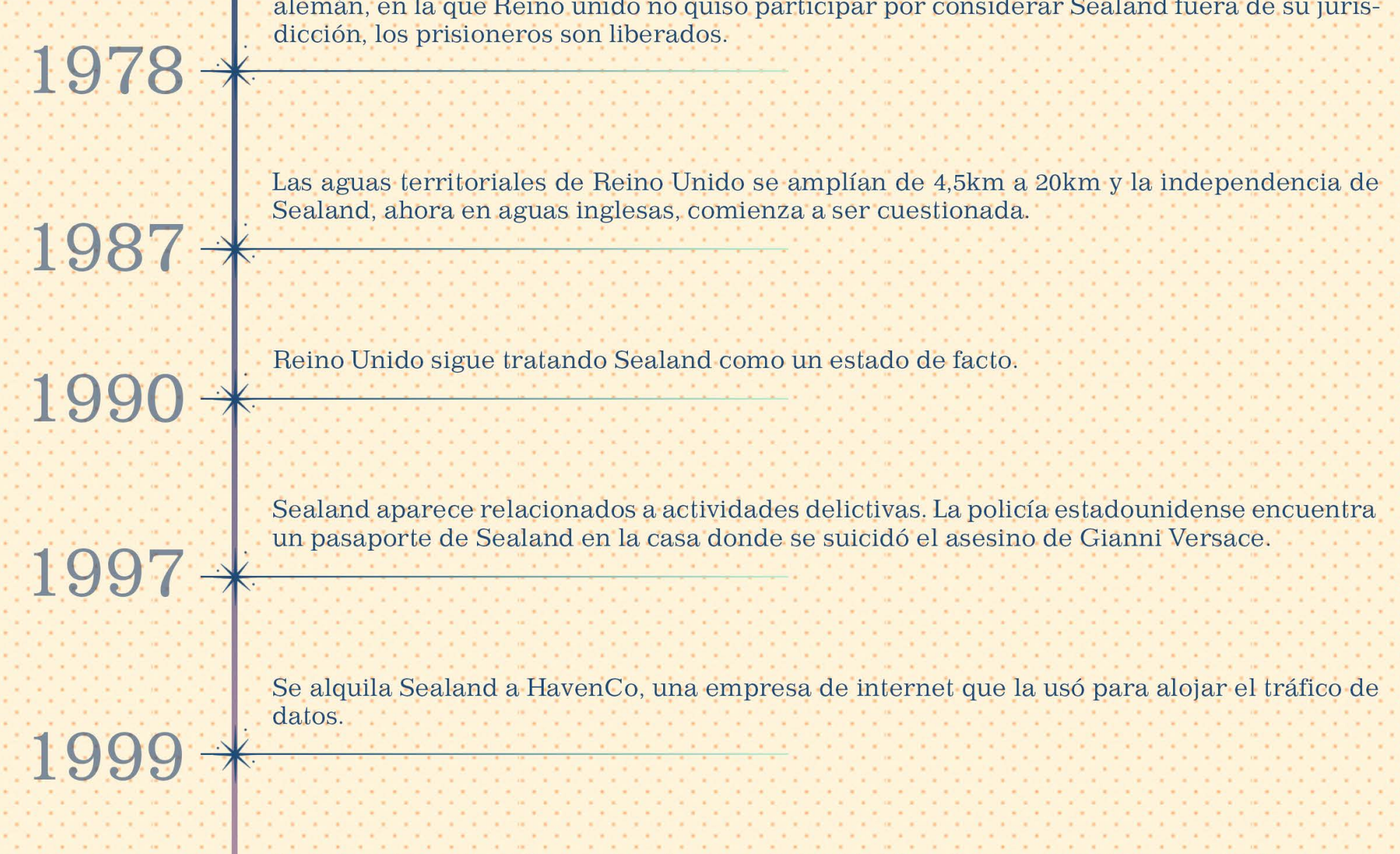

Es detenida en España una banda vinculada al tráfico de drogas y blanqueo de dinero. La a de pasaportes Se rastrean el origen de estas falsificaciones hasta uno de los alemanes que

2000






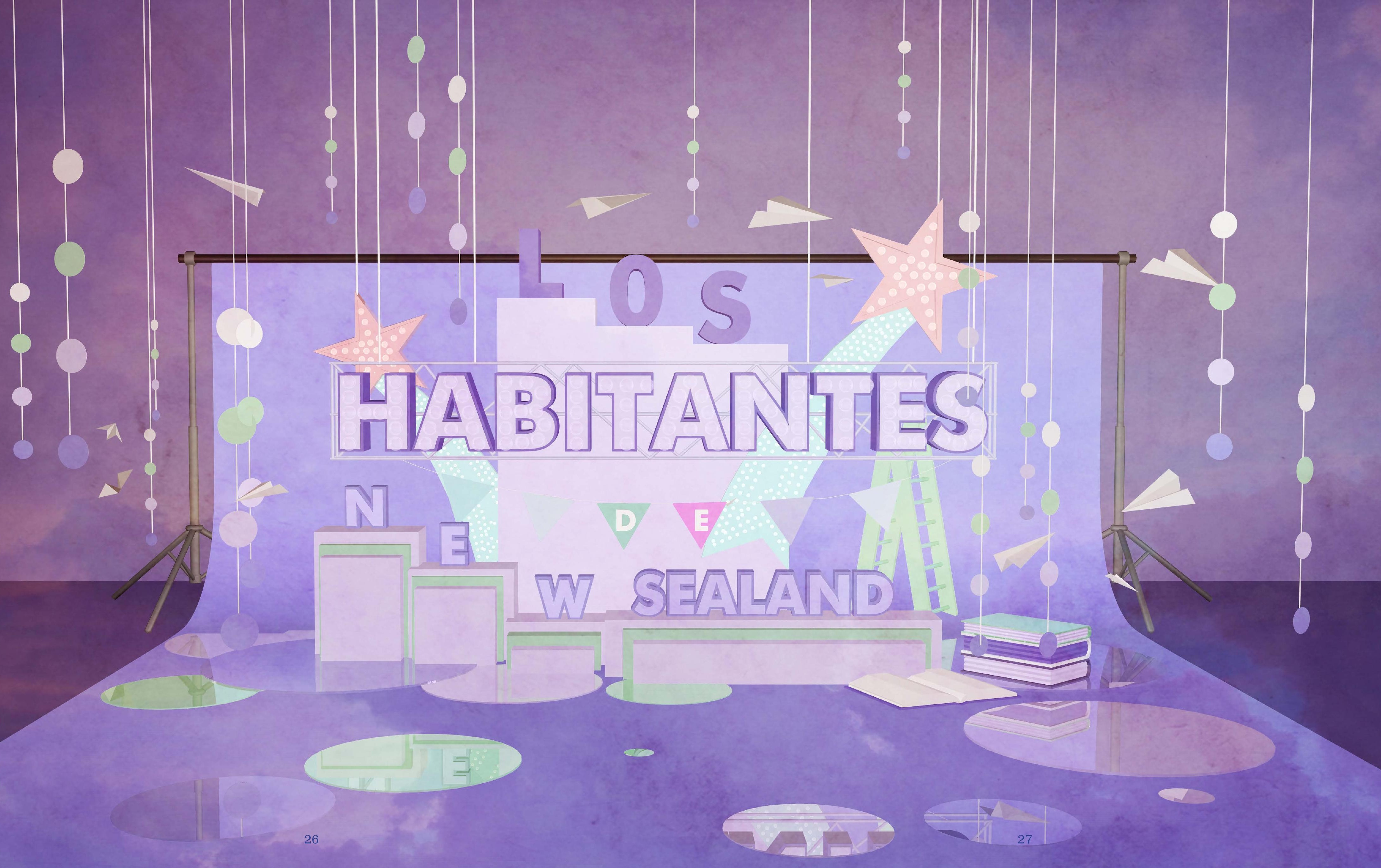









\section{Andrew Ryoun}

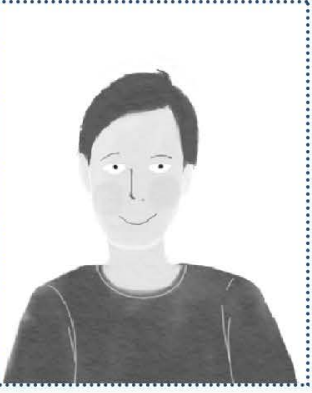

Como llegó a New Sealand: es considerado su fundador

Te pañis importantes del momento

trinew Sealand: de todo un poco.

ema: equivocarse es una opción.
no estás innovando lo suficiente.

Reservella



Robert Banks

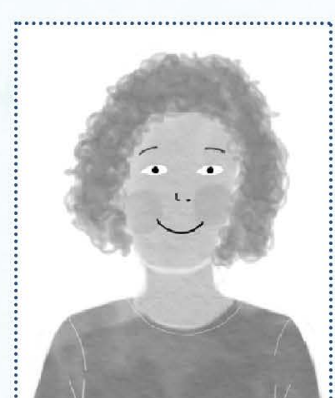

\section{Leona N. Philpot}

R

ómo llegó a New Sealand: invitada por Andrew Ryan tos subacuáticas.

. ma. si te rapido del mundo.

ma: si te levantas por la mañana y piensas que el
turo va a ser mejor, es un buen día.

\section{Team Nemo}

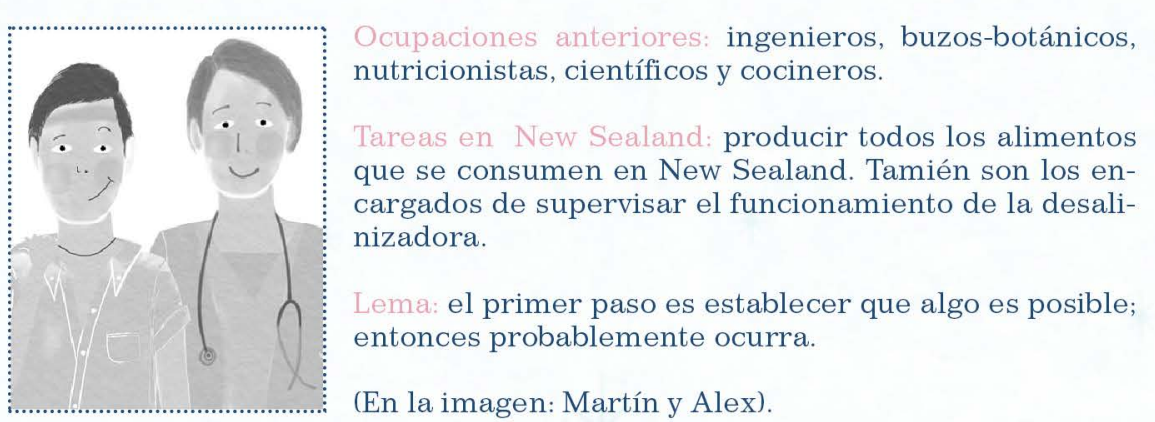

Sean Hastings

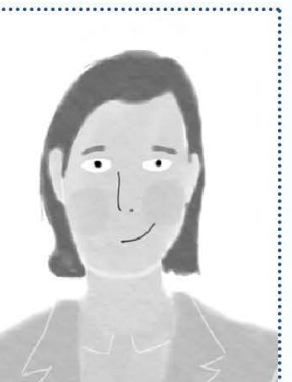

Dordana \& Patricia
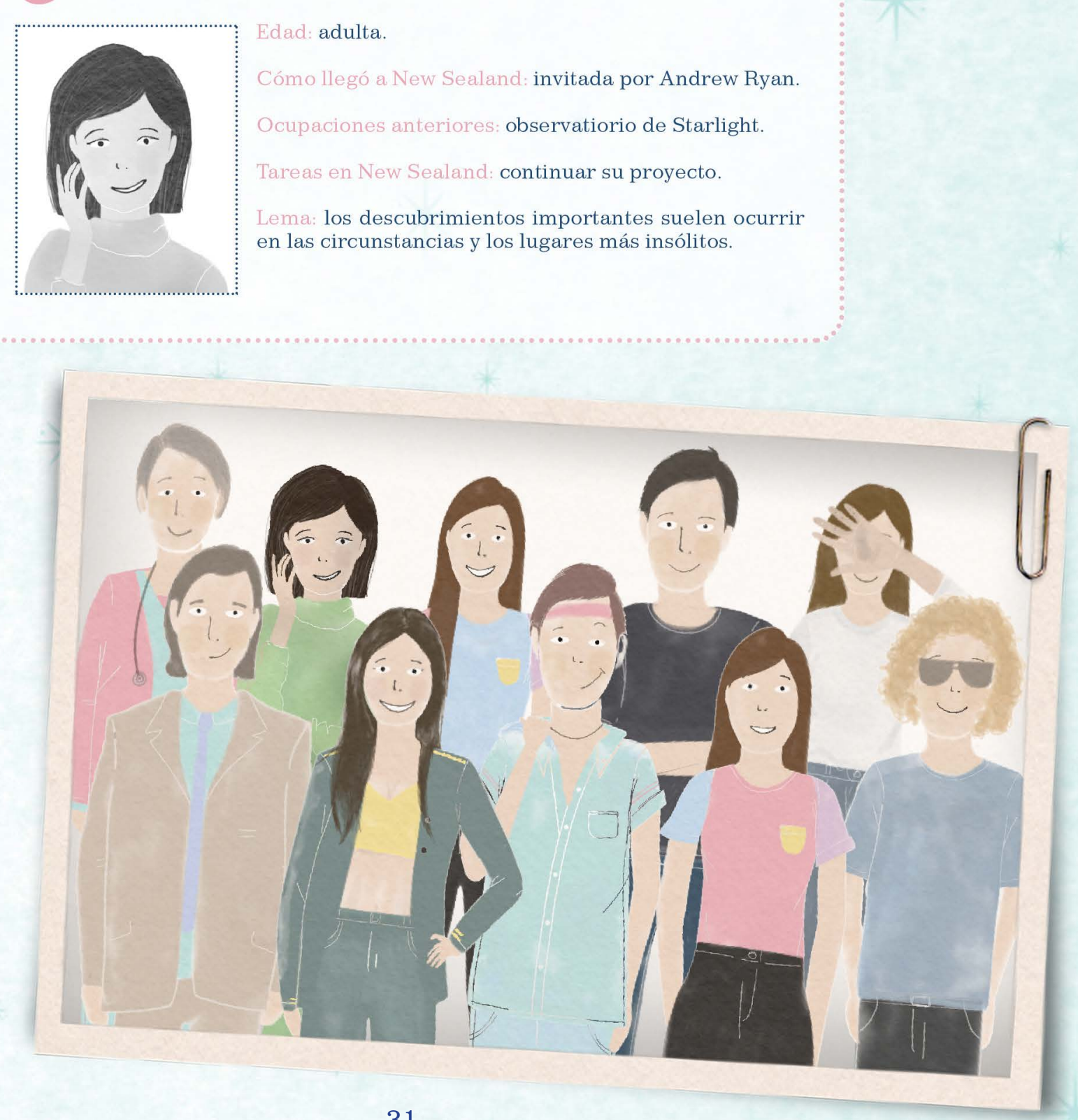



\section{Dessica Lautner}




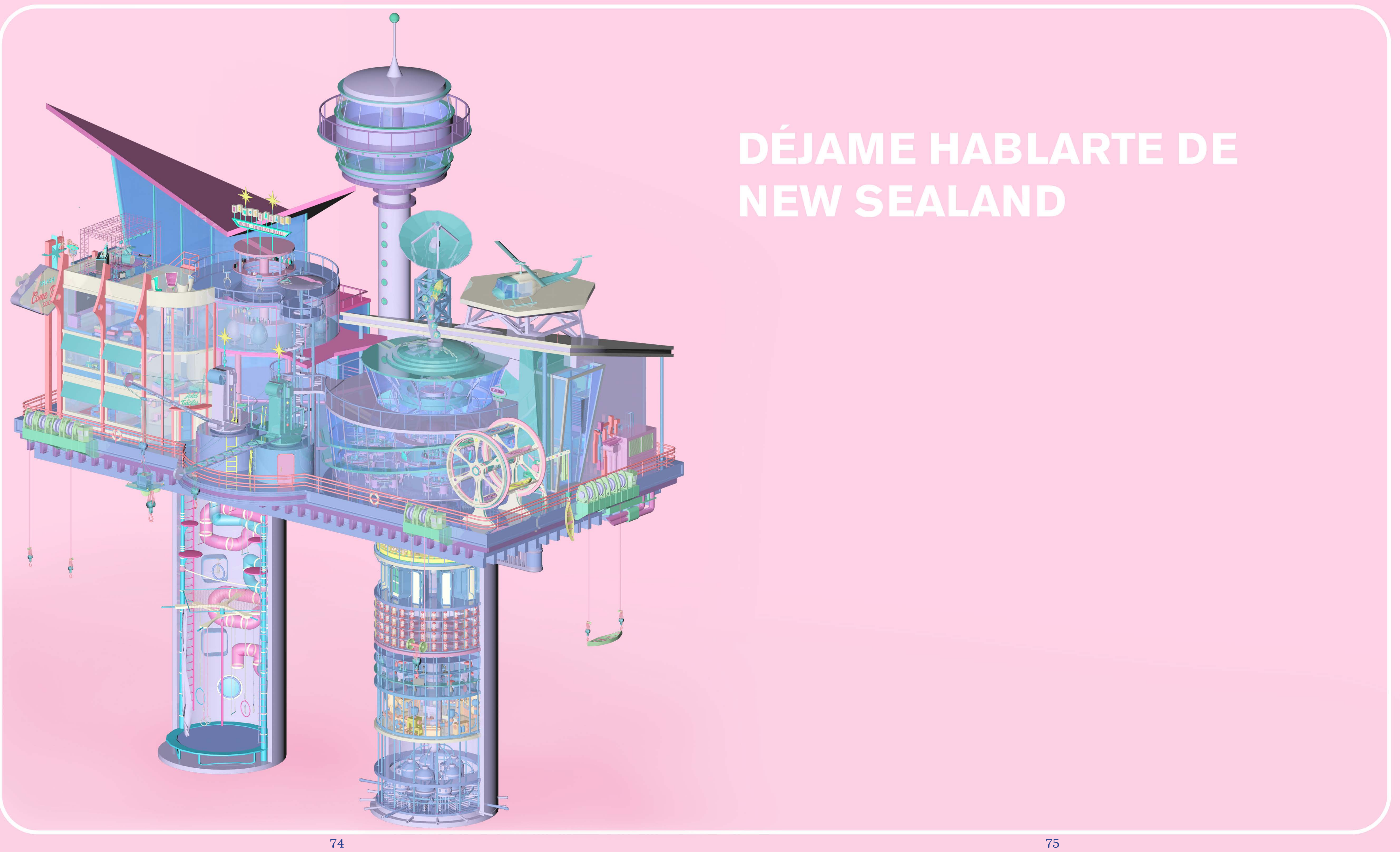






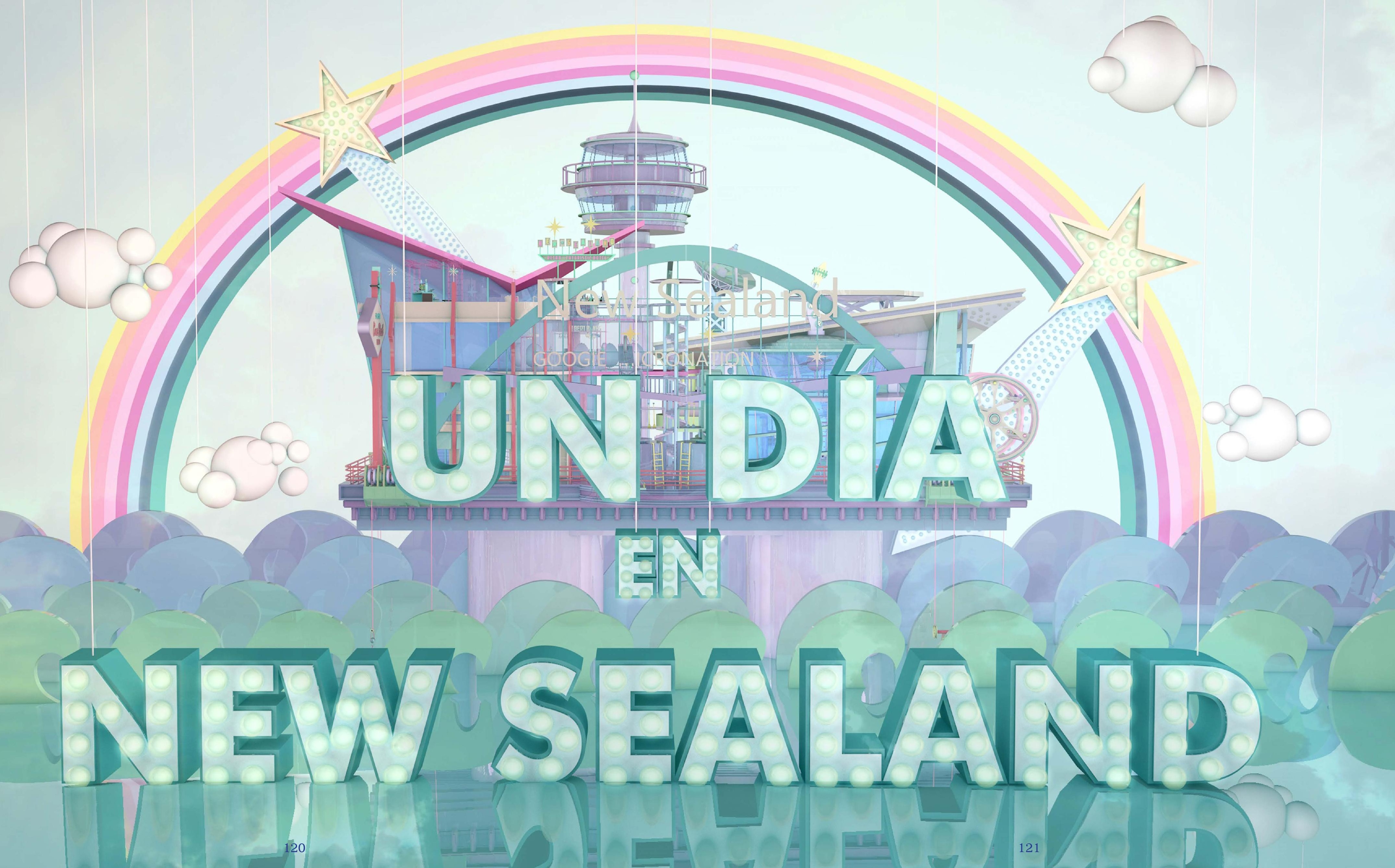




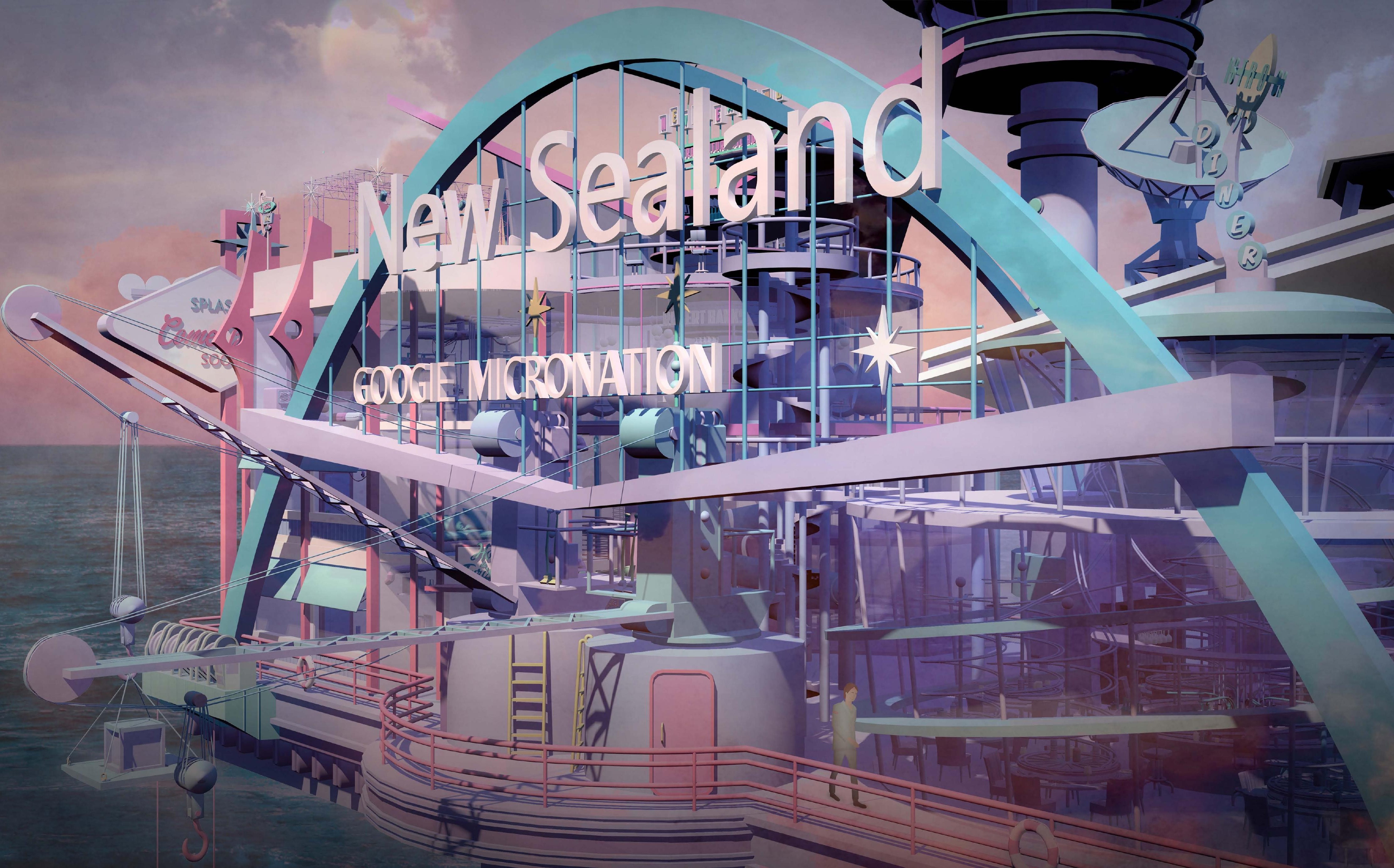














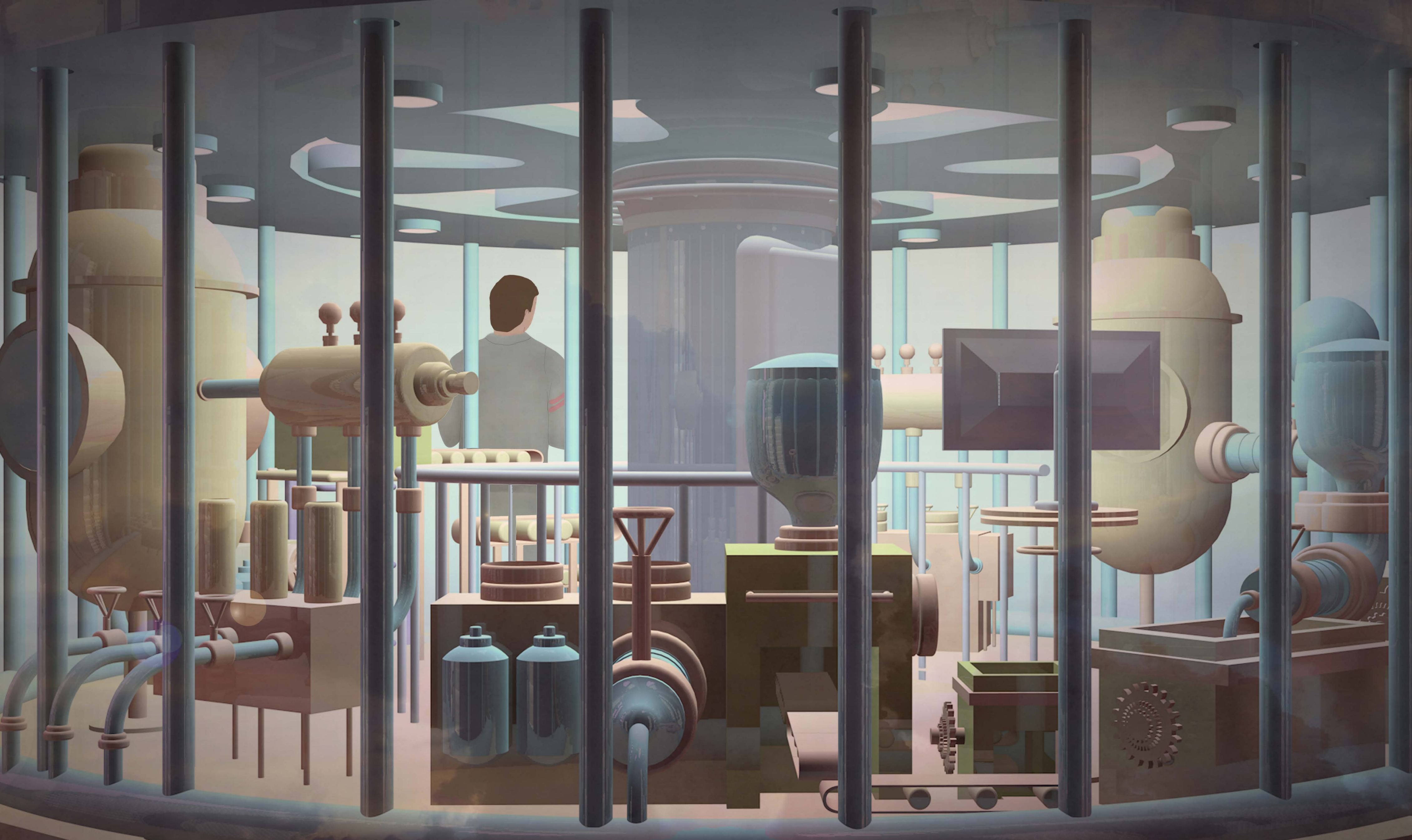









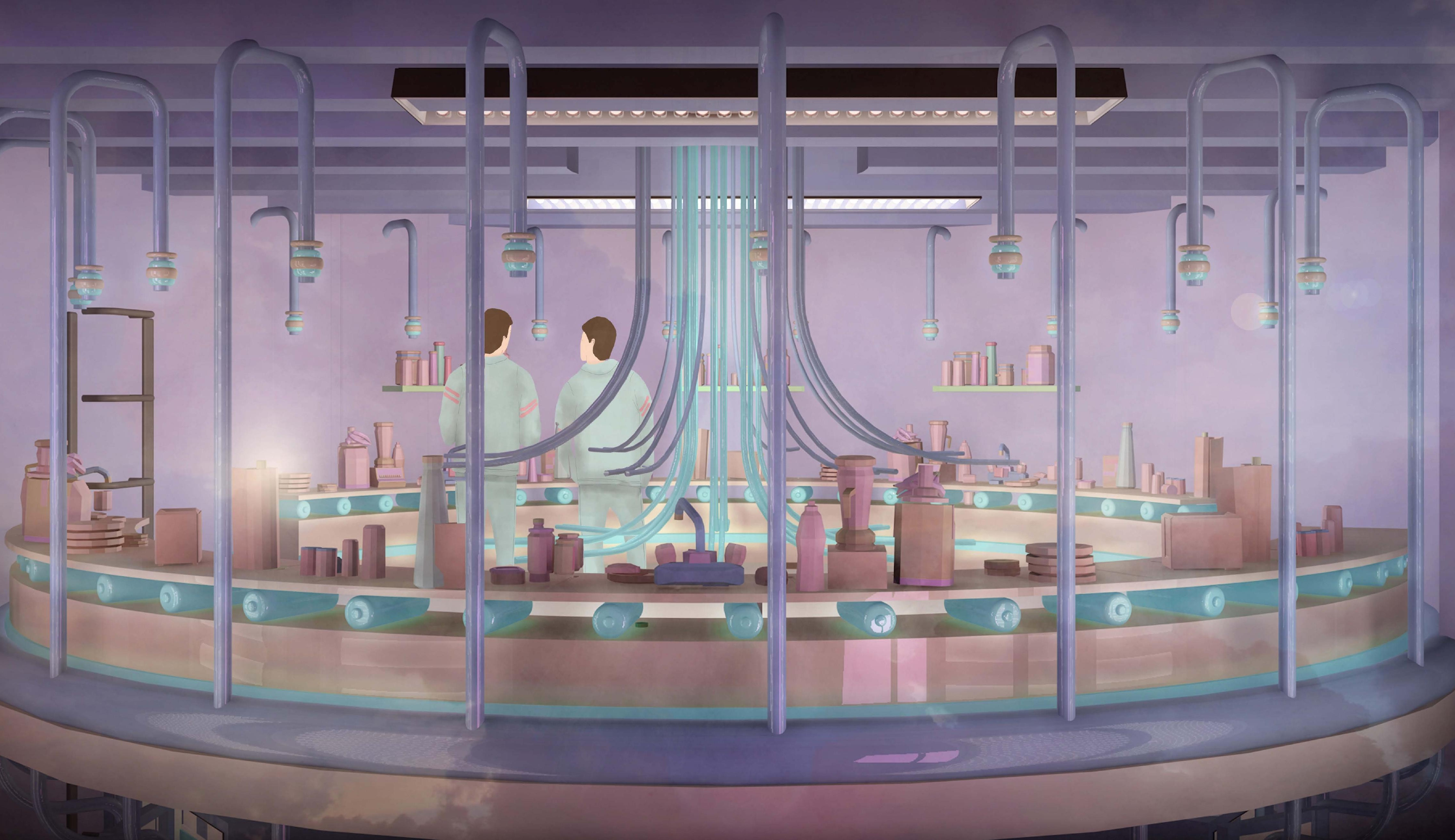









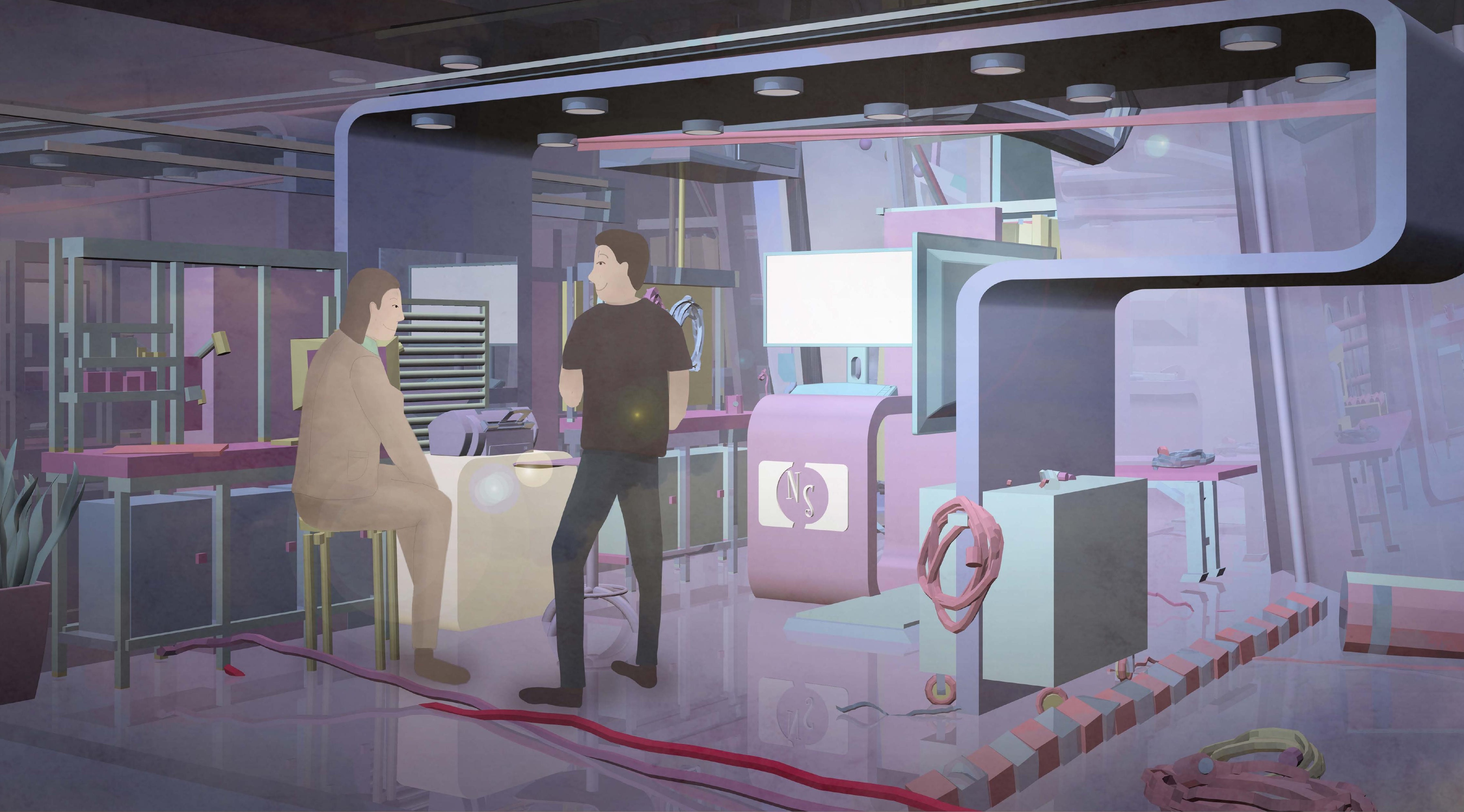




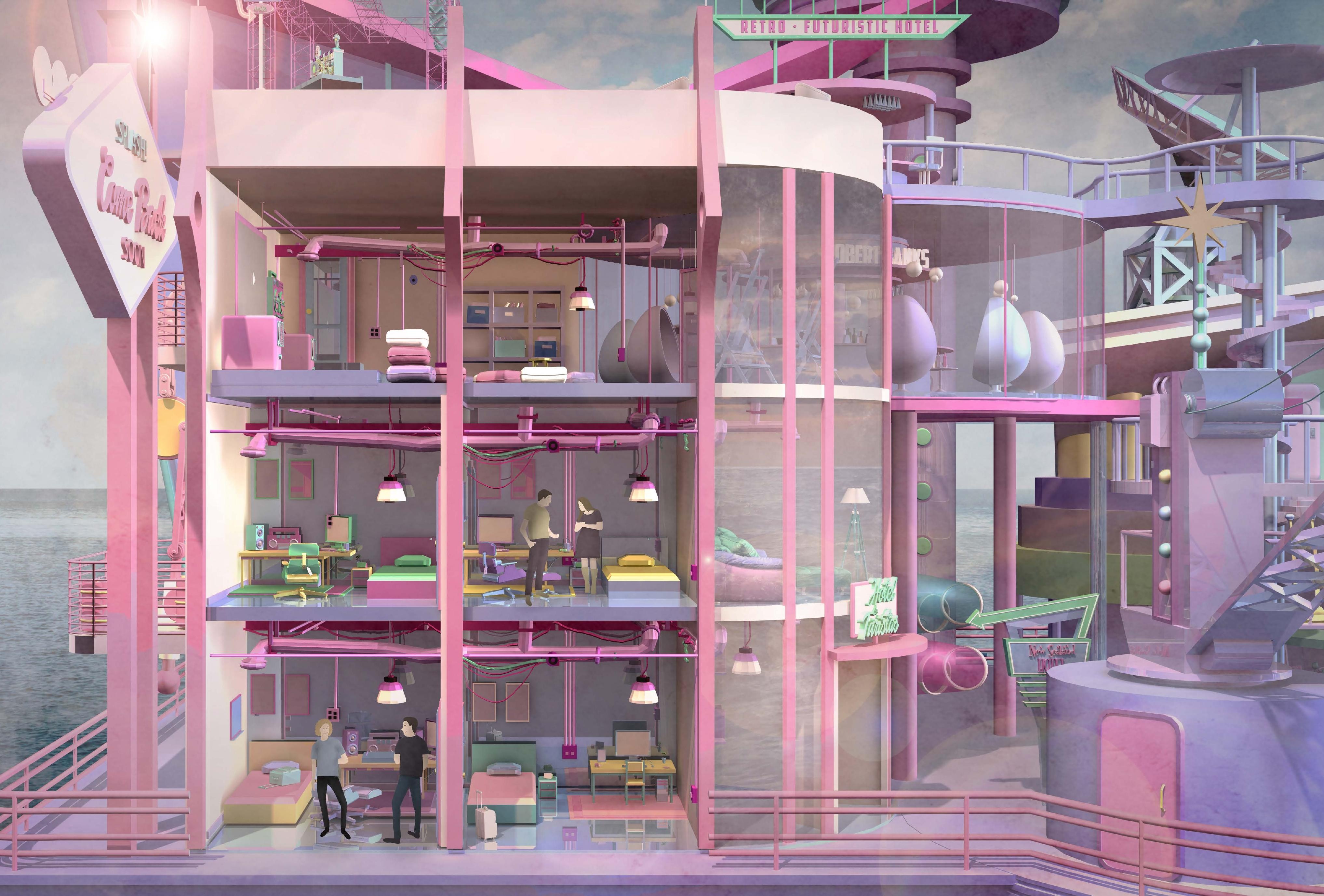




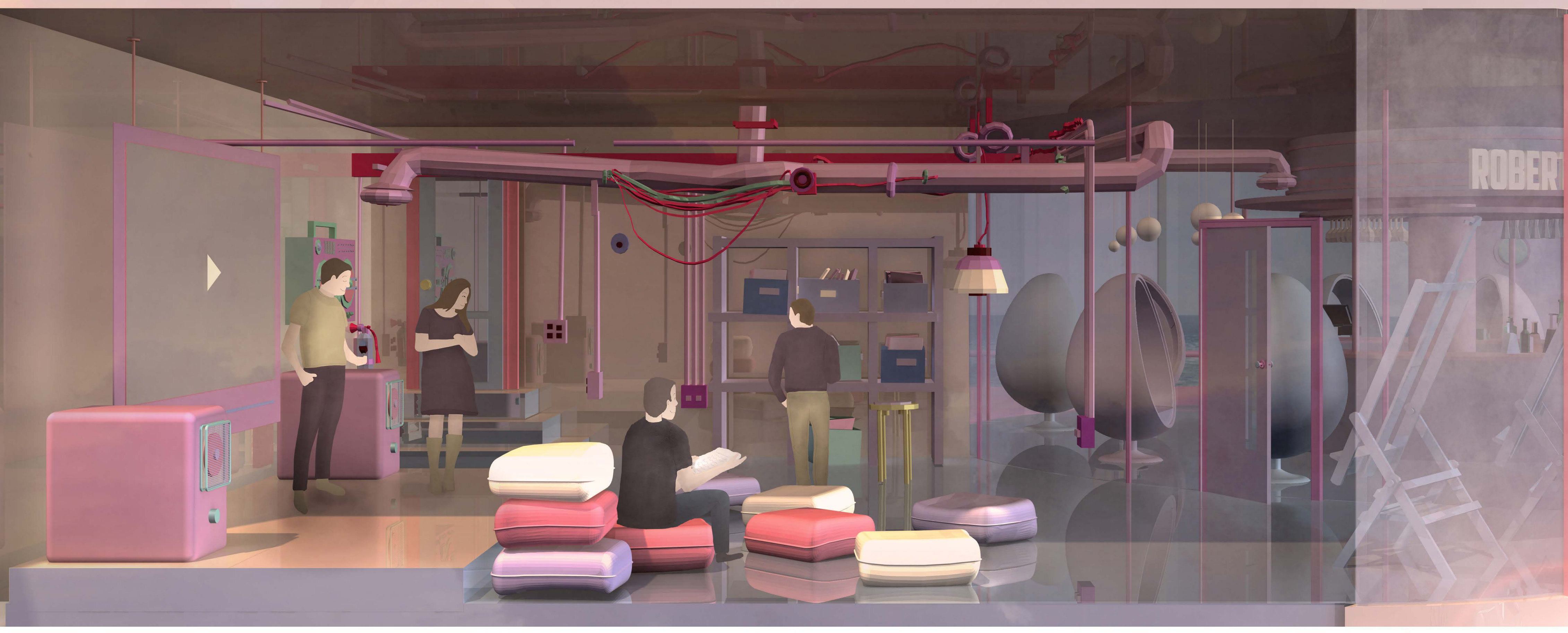




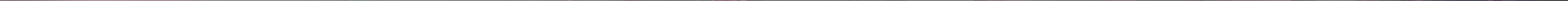




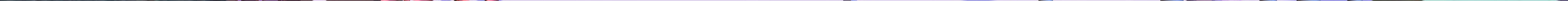




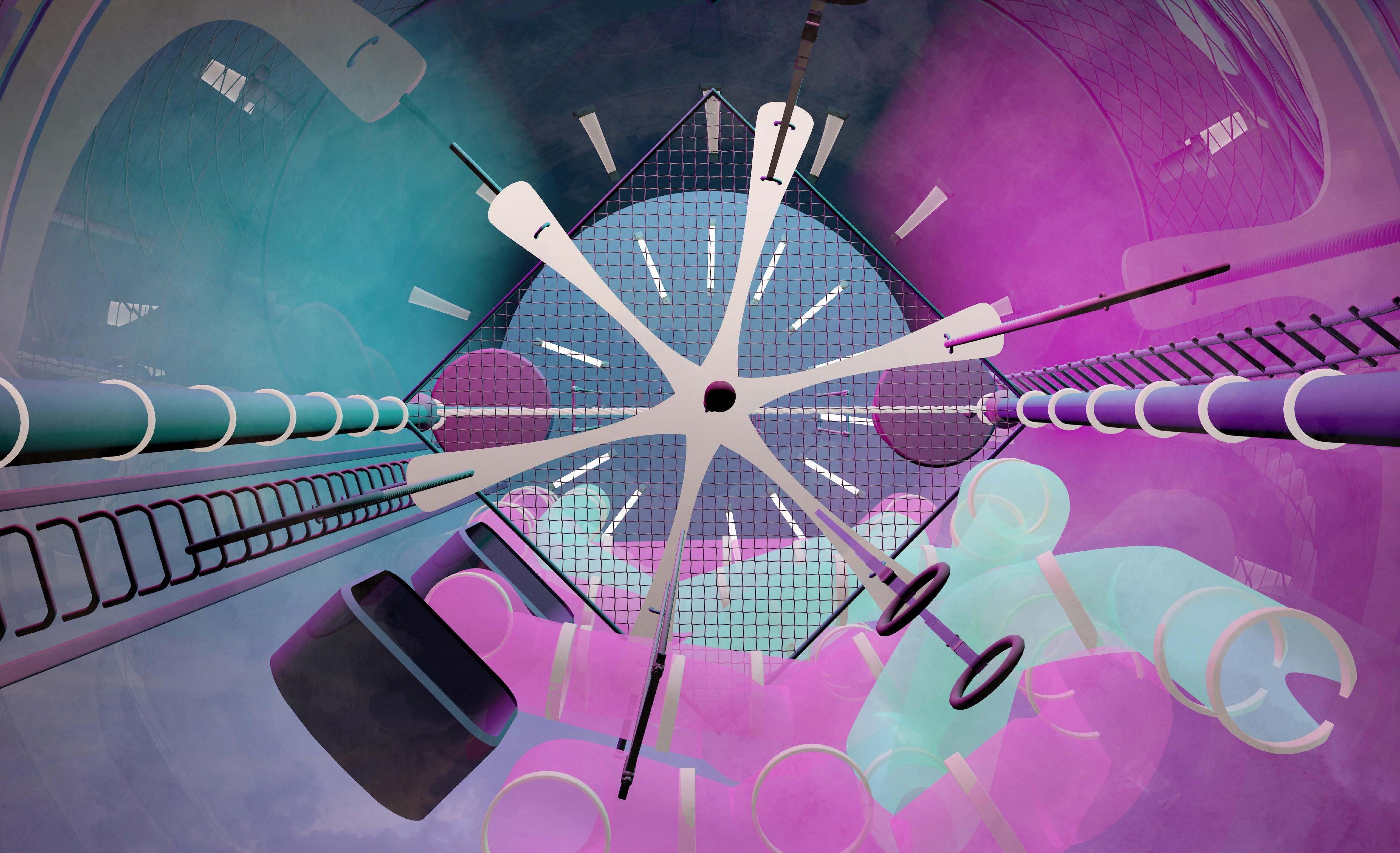









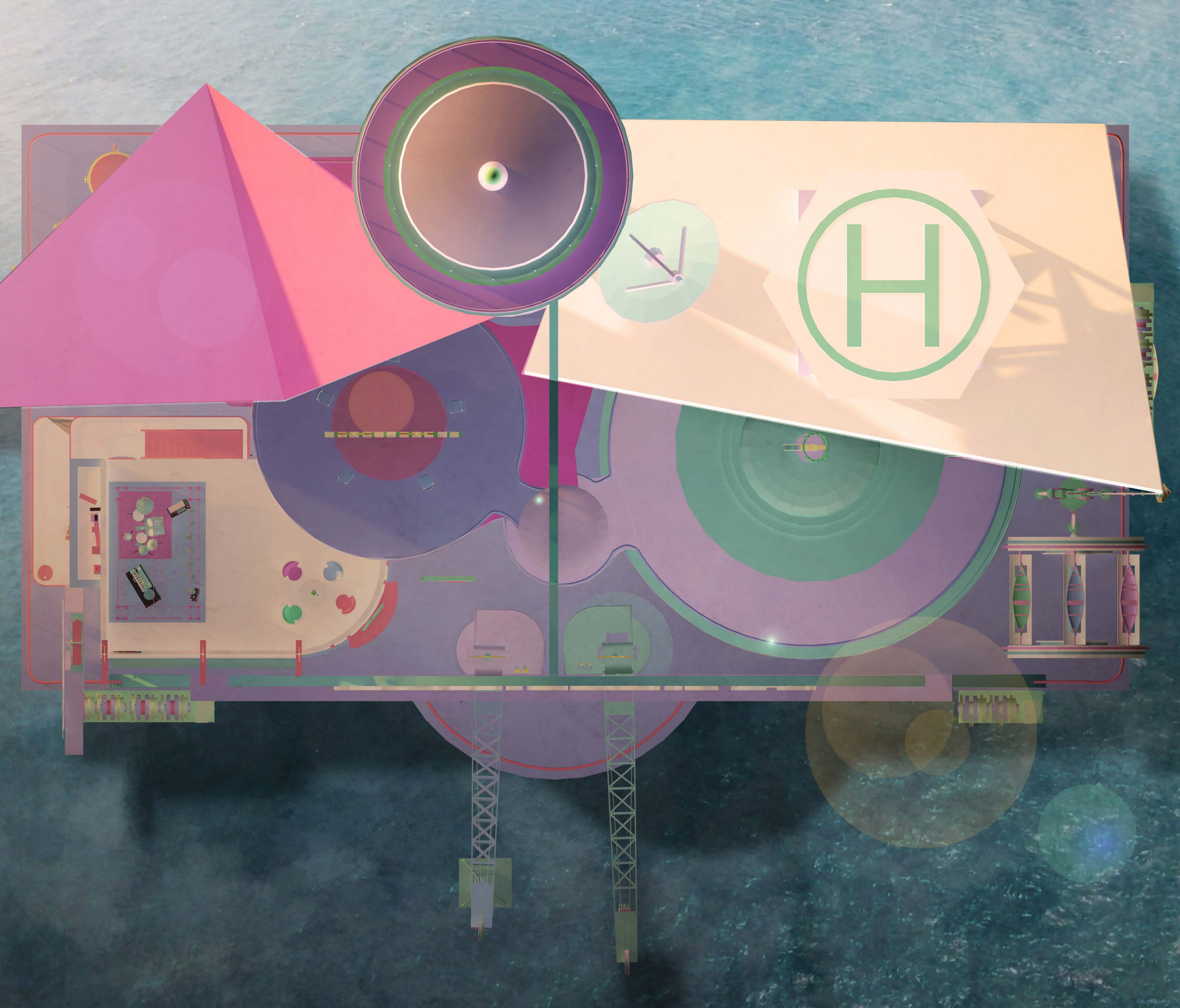




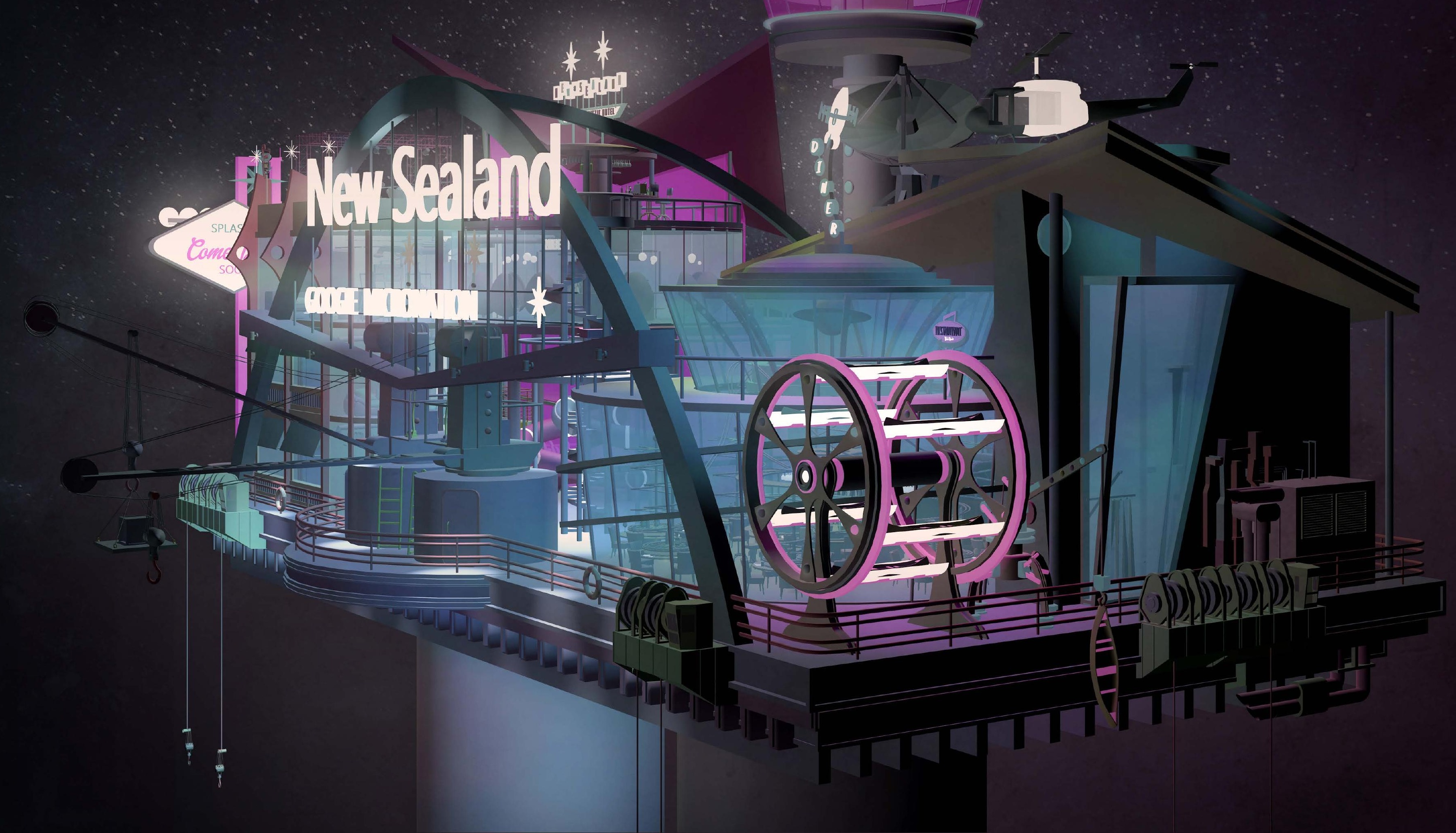




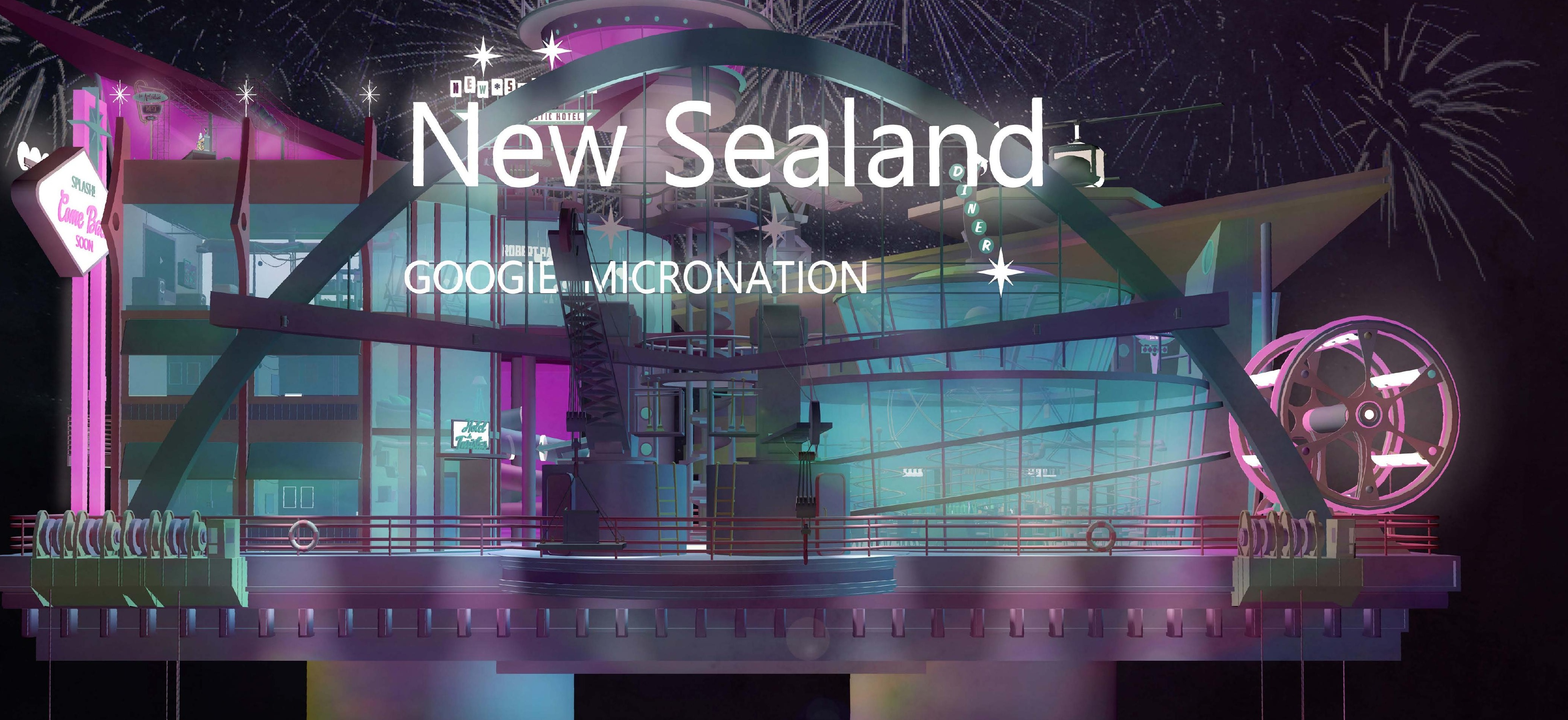




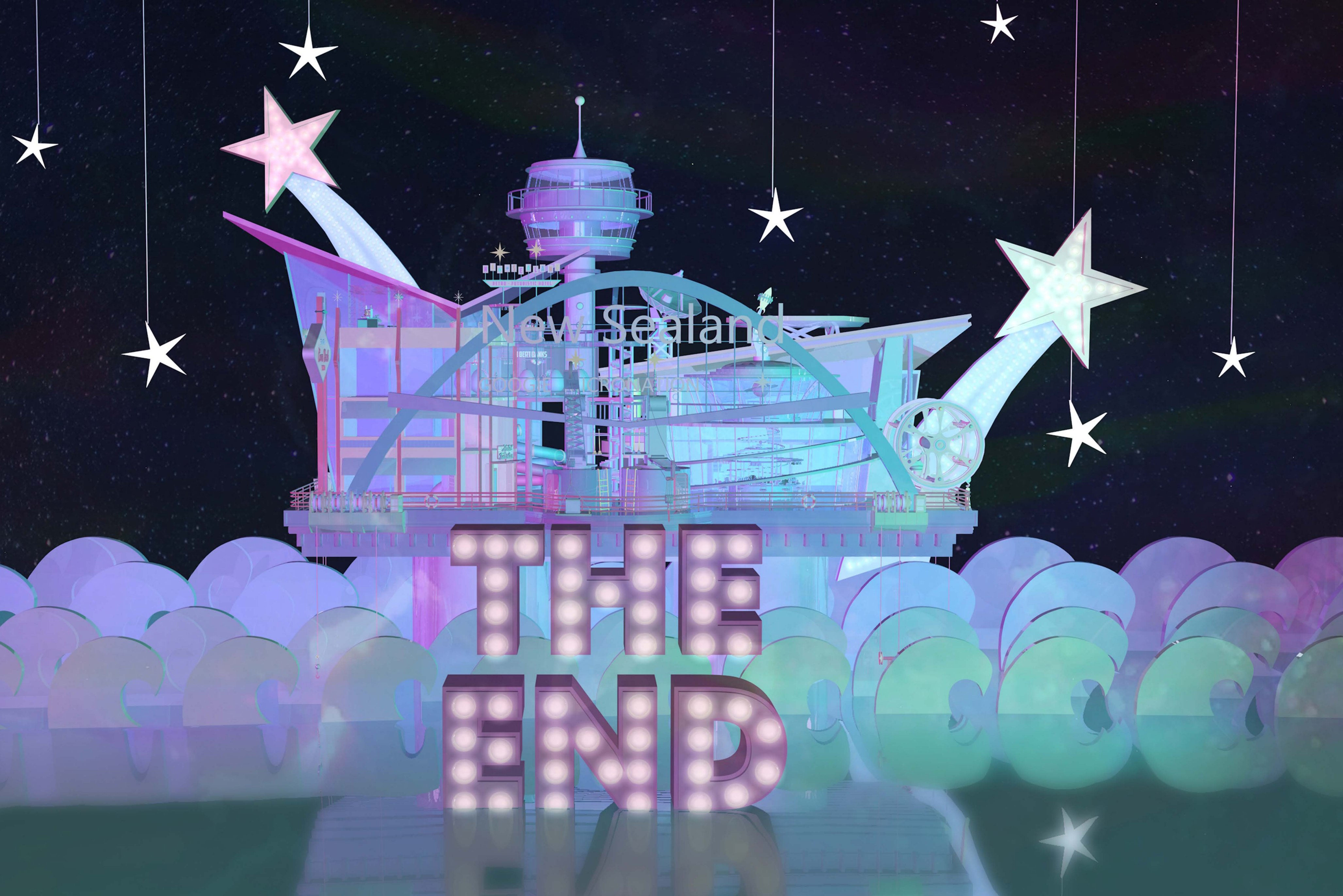




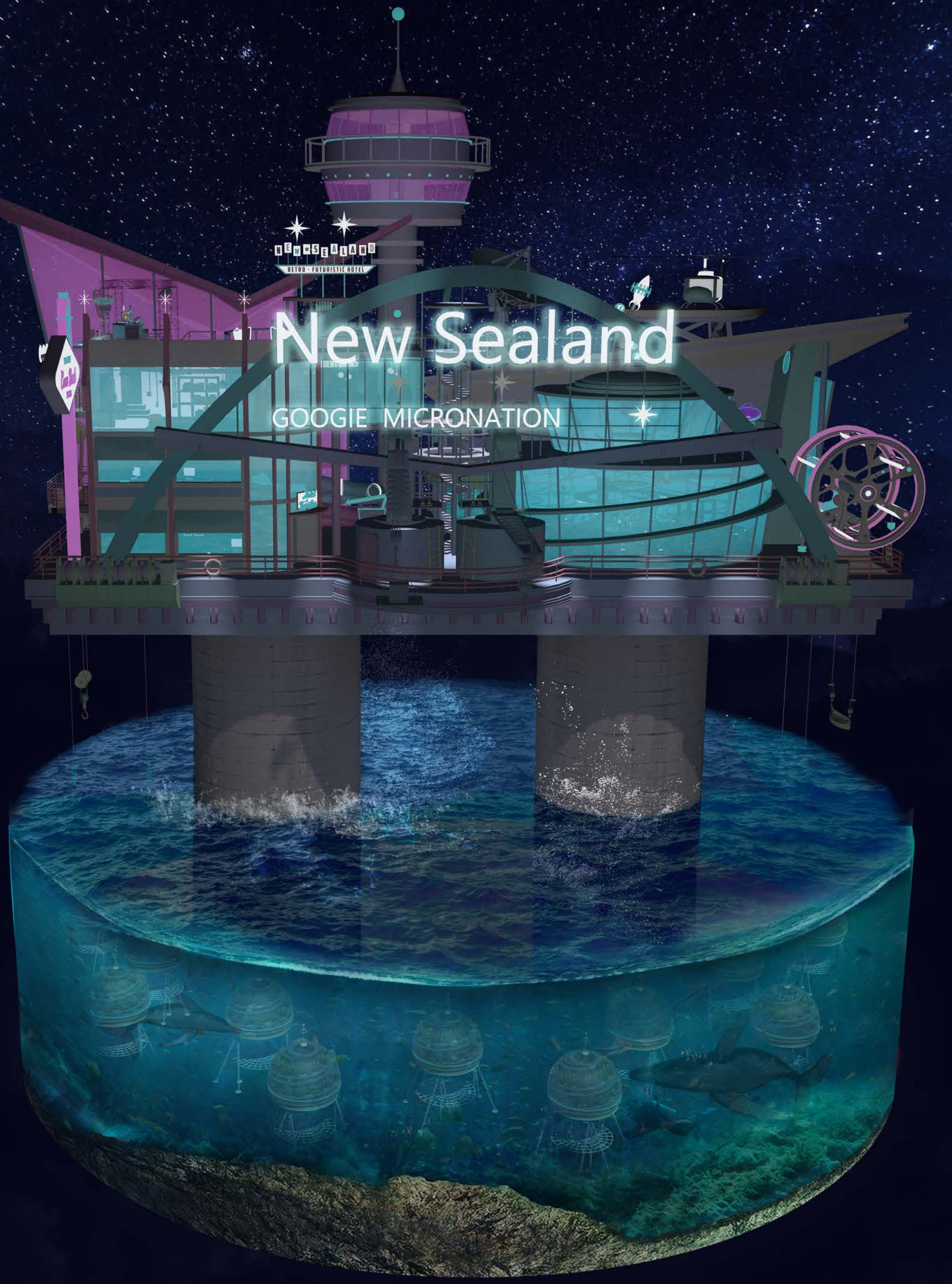

